\title{
HIV-1 versus SARS-CoV-2 infection: understanding the population genetic aspects of drug inefficacy (especially ivermectin) in the integrase-importin complex
}

Pierre Teodosio Felix ( $\nabla$ pierre.felix@hotmail.com )

Laboratory of Population Genetics and Computational Evolutionary Biology - LaBECom, UNIVISA https://orcid.org/0000-0002-9159-7206

\section{Research Article}

Keywords: HIV-1, Integrase, SARS-CoV-2, Ivermectin, Phylogeny, AMOVA

Posted Date: August 24th, 2020

DOl: https://doi.org/10.21203/rs.3.rs-63258/v1

License: (c) (1) This work is licensed under a Creative Commons Attribution 4.0 International License. Read Full License 


\section{Abstract}

Therapies with new drugs have been appearing in tests worldwide as potential inhibitors of sars-cov-2 virus replication. Recently, one of these drugs, Ivermectin, was reported as an inhibitor of the nuclear import of HIV-1 proteins in vitro, soon becoming the target of an international prospecting work (not yet published), with patients tested for COVID-19. However, understanding the evolutionary aspects of the biological components involved in the complex drug-nuclear import helps in understanding how these relationships exist in the deactivation of viral infections. Thus, 153 sequences of the HIV-1 integrase gene were analyzed for their genetic structure and molecular diversity and the presence of two distinct groups for the Gene and not only one, was detected; As well as different degrees of structuring for each of these groups. These results support the interpretation of the lack of conservation of the HIV-1 gene and that the number of existing polymorphisms, only for this structure of the complex, implies the non-efficiency of a drug at population levels. Thus, the molecular diversity found in HIV-1 can be extrapolated to other viruses, such as Including, SARS-CoV-2 and the functionality of the drug, interacting with the integraseimportin complex, can be further decreased.

\section{Introduction}

As a flattening measure of the growth curve of the number of cases of COVID-19 in Brazil, the recommendations of the Ministry of Health continue to be limited to the monitoring and containment of the virus as well as to those of maintaining social distancing, the use of face protection masks and constant hand washing. These recommendations, which follow the recommendations of all the world's health agencies, seem to be the most effective to inhibit the outbreak of this pandemic, which, as a direct consequence of non-control, would result in the breakdown of our health system (MINISTÉRIO DA SAÚDE, 2020).

However, a number of therapies are in tests worldwide and these range from vaccines to the use of some drugs (WHO, 2020). With regard to the new drugs tested to combat COVID-19, a not-so-new one (for other treatments) called IVERMECTIN, figured as an alternative for its power to inhibit the replication of the SARS-CoV-2 virus in vitro. Ivermectin, a pre-tested food and drug administration (FDA) for antiparasitic use, demonstrated broad-spectrum antiviral activity in vitro for the SARS-CoV-2 virus, and even two hours after infection was able to reduce the amount of viral RNA by approximately 5,000 times after 48 hours. This made ivermectin a candidate for in-depth investigations for possible human benefits (CALY, L. et al., 2020).

Even thinking about the "in vitro" characteristics of the study with ivermectin, its usefulness and potentiality as therapy did not reach exhaustion. Contrary to some drugs such as Chloroquine and hydroxichloroquine, discarded by who and many health agencies and research centers around the world, it ended up becoming a target in an international, multicenter and observational prospecting work, 
controlled on a case-by-case basis, using data collected from patients diagnosed with COVID-19 between January 1 and March 31,2020. These patients were exposed to doses of Ivermectin compared to patients with COVID-19 who received medical treatment without ivermectin. In this study (in vivo) and not yet published, the researchers assume that, in addition to being safe for use, the administration of ivermectin in patients hospitalized with COVID-19 was directly associated with the fact that a lower mortality and a shorter length of hospital stay, making the difference in the survival of hospitalized patients (PATEL A.N. et al., 2020).

The question then became the understanding of how ivermectin acted in the inhibition of the SARS-CoV-2 virus, since as an antiparasitic agent the issue of its antiviral activity was still unknown. In some studies (BOLDESCU et al, 2017; CALY et al, 2020; FRIEMAN et al, 2007; CAO et al., 2020; GREIN et al., 2020; FERNER et al., 2020; CRUMP et al., 2017), ivermectin had been reported as an inhibitor of the nuclear import of viral proteins, as the non-structural protein of the tumor antigen of the ape virus SV40 (an old known molecular biology as cloning vector in ancient techniques of recombinant DNA technology), and also acting in the limitation of infections of other RNA viruses such as viruses of types 1 to 4 of dengue, West Nile, Venezuelan equine encephalitis and influenza. Until, in studies with the HIV-1 virus (human immunodeficiency virus type 1), it was finally associated with the breakdown of the interaction between the ENZYME INTEGRASE of the HIV-1 virus and the heterodimer a / $\beta 1$ of IMPORTIN, which is the protein responsible for the nuclear import of the INTEGRASE itself.

Since the decade of 1990, the role of integrase as an inhibitor of HIV replication has been suggested by scientists as a promising opportunity in the treatment of viral infections because it is a highly conserved enzyme from an evolutionary point of view and therefore with less genetic variability (SPRINZ, E. 2016). Because it is very conserved, it has greater difficulty in selecting mutations associated with resistance, besides presenting potential synergism with other RNA viruses, including those viruses that had resistance to reverse transcriptase inhibitors. (PURAS L. et al, 1995); (ROBINSON, W.E., 1998) (BEALE K.K., ROBINSON W.E. JR. 2000); (REINKE R, STEFFEN N.R., ROBINSON W.E. JR. 2001)

Although it has been tested in humans for three decades (SMART, T. 1996), its development has been quite "truncated" by the high cost of production and its pharmacokinetic limitations (such as low selectivity due to integrase, difficulties encountered in its injectable use and short half-life time) preventing its clinical use (SPRINZ, E. 2016). However, understanding the evolutionary aspects of this enzyme can help the scientific community understand what possible relationships exist between it and the drugs that interact in its connection with IMPORTIN, especially in the role of destabilization of the import complex that disables viral infections, such as ivermectin. Thinking like this, the team of the Laboratory of Population Genetics and Computational Evolutionary Biology (LaBECom-UNIVISA) designed a study of phylogeny and molecular variance analysis to evaluate the possible levels of genetic diversity and polymorphisms existing in a PopSet of the integrase gene of human immunodeficiency virus 1 collected in a Russian population of Kyrgyzstan and available at GENBANK.

\section{Objective}


Evaluate the possible levels of genetic diversity and polymorphisms existing in 153 sequences of the integrase gene of human immunodeficiency virus 1 in the Kyrgyzstan population.

\section{Methodology}

3.1 Databank: The 153 gene sequences of the integrase gene of human immunodeficiency virus 1 were collected from GENBANK (https://www.ncbi.nIm.nih.gov/popset/?term=MN888087.1 and participate in a PopSet dipped by Totmenin and collaborators on March 25, 2020 (Popset:1822236350).

3.2 Phylogenetics Analyses: For phylogenetic analyses, the previously described nucleotide sequences were The sequences were aligned using the MEGA X program (TAMURA et al., 2018) and gaps were extracted for the construction of phylogenetic trees.

3.3 Genetic Structuring Analyses: Paired FST estimators were obtained with the software Arlequin v. 3.5 (EXCOFFIER et al., 2005) using 1000 random permutations. The FST matrix generated by the software was used in the construction of a dendrogram based on the UPGMA distance method with the MEGA X software (TAMURA et al., 2018) and the FST and geographic distance matrices were not

\section{Results}

\subsection{General properties of integrase gene sequences of the HIV-1 human virus}

Of the 153 sequences of the gene segment of the integrase gene of human immunodeficiency virus 1 with $882 \mathrm{bp}$ of extension, the analyses revealed the presence of 343 polymorphic sites and of these, 70 sites were parsimoniously informative. The graphical representation of these sites could be seen in a logo built with the WEBLOGO 3 program (CROOKS et al., 2004), where the size of each nucleotide is proportional to its frequency for certain sites. (Figure 1).

Using the UPGMA method, based on the 70 parsimony-informative sites, it was possible to understand that the 153 haplotypes comprised two distinct groups, here called Bishkek and Osh, in reference to their collection origin and no haplotype sharing was observed between the two groups (Figure 2).

\subsection{Genetic Distance Analysis}

Analyses based on FST values also confirmed the presence of two distinct genetic entities, with a component of variation greater than $36 \%$ and with $p$ value lower than 0.05 with significant evolutionary divergences within the groups (table 1) and also evidenced a high genetic similarity between the sequences that comprised the Oshi group, as well as a greater evolutionary divergence between the sequences that comprised the Bishkek group (table 2); (table 3). 
Table 1. Paired FST values for the 153 sequences of the integrase gene of human immunodeficiency virus 1 with 882 bp extension.

$\begin{array}{lll}\text { Populations Bishkek Osh } & \text { B }\end{array}$

Bishkek

0.00000

0.36597

Osh

0.36597

0.00000

Table 2. Estimates of the mean evolutionary divergence within the groups. Number of base substitutions per location, the average of all sequence pairs within each group.

$\begin{array}{lll}\text { Groups } & \text { Estimate average } & \text { Standar } \\ \text { Bishkek } & 0,23 & 0,05 \\ \text { Osh } & 0,09 & 0,01\end{array}$

Standard error estimates are shown above the diagonal. The analyses were performed using the maximum composite likelihood model [1]. This analysis involved 153 nucleotide sequences. All ambiguous positions have been removed for each sequence pair (pair exclusion option). There was a total of 70 positions in the final dataset. Evolutionary analyses were performed on MEGA X.

Table 3. Estimates of evolutionary divergence between groups.

$\begin{array}{llc}\text { Groups } & \text { Bishkek } & \text { Osh } \\ \text { Bishkek } & - & \mathbf{0 , 2 7} \\ \text { Osh } & \mathbf{0 , 2 7} & -\end{array}$

The number of base overrides per location of the average of all pairs of sequences between groups is shown. The analyses were performed using the maximum composite likelihood model [1]. This analysis involved 153 nucleotide sequences. All ambiguous positions have been removed for each sequence pair (pair exclusion option). There was a total of 70 positions in the final dataset. Evolutionary analyses were performed on MEGA X.

\subsection{Molecular Variance Analysis (AMOVA)}

Molecular variation analyses of the 153 sequences of the integrase gene of human immunodeficiency virus 1 revealed very significant FST values (FST $=0.36)$ when analyzed as distinct and even more significant groups when their internal differences were analyzed (in both groups) (Table 4). 
Table 4: Molecular Variance Analysis, applying Wright's FST (1969), for the 153 sequences of the integrase gene of human immunodeficiency virus 1 with 882 bp extension

\begin{tabular}{|c|c|c|c|c|}
\hline Variation source & $\begin{array}{l}\text { Degrees of } \\
\text { freedom. }\end{array}$ & $\begin{array}{l}\text { Sum of } \\
\text { squares }\end{array}$ & $\begin{array}{l}\text { Variation } \\
\text { components }\end{array}$ & $\begin{array}{l}\text { Percentage of } \\
\text { variation. }\end{array}$ \\
\hline $\begin{array}{l}\text { Among the } \\
\text { populations }\end{array}$ & 1 & 207.72 & $2.65 \mathrm{Va}$ & $36.6 \%$ \\
\hline $\begin{array}{l}\text { Within } \\
\text { populations }\end{array}$ & 151 & 694.62 & $4.60 \mathrm{Vb}$ & $63.4 \%$ \\
\hline TOTAL & 152 & 902.34 & 7.25 & \\
\hline
\end{tabular}

Tau variations (related to the ancestry of the two groups) revealed a significant time of divergence, supported by mismatch analysis of the observed distribution $(\tau=44 \%)$ and with constant mutation rates between localities (table 5).

Table 5. Tau $(\tau)$ values for the 153 sequences of the integrase gene of human immunodeficiency virus 1 with 882 bp extension

\begin{tabular}{|lll|}
\hline Populations & Bishkek & Osh \\
\hline Bishkek & 0.00000 & $\mathbf{1 . 7 2 0 3 3}$ \\
\hline Osh & $\mathbf{1 . 7 2 0 3 3}$ & 0.00000 \\
\hline
\end{tabular}

\subsection{Molecular diversity analyses}

Molecular diversity analyses estimated by $\theta$ reflected a significant level of mutations among all haplotypes (transitions and transversions). Indel mutations (insertions or deletions) were not found in either of the two groups studied. The D tests of Tajima and Fs de Fu showed disagreements between the estimates of general $\theta$ and $\pi$, but with negative and highly significant values, indicating an absence of population expansion. The irregularity index ( $R=$ Raggedness) with parametric bootstrap simulated new values $\theta$ for before and after a supposed demographic expansion and in this case assumed a value equal to zero for the groups (Table 6); (Table 7). 
Table 6. Molecular Diversity Indexes for the 153 sequences of the integrase gene of human immunodeficiency virus 1 with 882 bp extension

\begin{tabular}{|lll|}
\hline Indexes & Bishkek & Osh \\
\hline Transitions & 22 & 17 \\
\hline Transversions & 12 & 03 \\
\hline Replacements & 34 & 20 \\
\hline Indels & 0 & 0 \\
$\pi$ & 8.6 & 6.1 \\
$\theta S$ & 8.1 & 5.4 \\
$\theta S($ d.p) & 2.7 & 2.0 \\
$\theta \pi$ & 8.6 & 6.1 \\
$\theta \pi($ d.p) & 4.5 & 3.3 \\
\hline
\end{tabular}


Table 7. Neutrality tests for the 153 sequences of a segment of the integrase gene of human immunodeficiency virus 1 with 882 bp extension

$\begin{array}{llll}\text { Test Bishkek } & \text { Osh } & \text { Average }\end{array}$

\section{Ewens-Watterson}

Number of Alleles

76

77

76.50000

0.70711

Chakraborty's

Expected Number of Alleles

24.96770

16.04377

20.50573

6.31017

Tajima Test

\begin{tabular}{lllll} 
Sample Size & 76 & 77 & 76.50000 & 0.70711 \\
\hline S & 65 & 61 & 63.00000 & 2.82843 \\
\hline$\pi$ & 12.56035 & 5.88448 & 9.22242 & 4.72055 \\
\hline D de Tajima & $-0.17584-$ & -1.74039 & 0.95812 & 1.10631 \\
\hline D de Tajima (p-value) & 0.48800 & 0.01400 & 0.25100 & 0.33517
\end{tabular}

\section{FU'S and FS Test}

\begin{tabular}{|lllll|}
\hline Number of Alleles & 76 & 77 & 76.50000 & 0.70711 \\
\hline$\theta \pi$ & 12.56035 & 5.88448 & 9.22242 & 4.72055 \\
\hline Expected number of alleles & 24.96770 & 16.04377 & 20.50573 & 6.31017 \\
\hline FS & $-24.32473-$ & -25.26472 & 24.79472 & 0.66468 \\
\hline FS (p-value) & 0.00000 & 0.00000 & 0.00000 & 0.00000 \\
\hline
\end{tabular}

\section{Discussion}

As the use of phylogenetic analysis and population structure methodologies had not yet been used in this PopSet, in this study it was possible to detect the existence of these two distinct groups for the integrase gene of human immunodeficiency virus 1 in the Kyrgyz region. The groups described here seem to correspond to two HIV-1 subpopulations that co-exist in the same locality and that had their genetic distances supported by FST analyses using the marker in question and its structure sufficiently significant for such interpretation. Different degrees of structuring were detected for each group, being essentially smaller among one of them (Bishkek). These data suggest that the high degree of structuring present in Oshi may be related to a loss of intermediate haplotypes over the generations, possibly associated with an absence of gene flow.

These levels of structuring were also supported by simple phylogenetic pairing methodologies such as UPGMA, which in this case, with a discontinuous pattern of genetic divergence between the groups 
(supporting the occurrence of geographic undercalculations resulting from past fragmentation events), was observed a large number of branches with many mutational steps. These mutations possibly settled by drift due to the founding effect, which accompanies the dispersal behavior and/or loss of intermediate haplotypes over the generations. The values found for genetic distance support the presence of this discontinuous pattern of divergence between the studied groups, since they considered important the minimum differences between the groups, when the haplotypes between them were exchanged, as well as the inference of values greater than or equal to that observed in the proportion of these permutations, including the $p$ value of the test.

The discrimination of the two genetic entities in the same locality was also perceived when the interhaplotypic variations were hierarchized in all covariance components: by their intra and interindividual differences or by their intra- and intergroup differences, generating dendrograms that supported the idea that the significant differences found in the Bishkek group, for example, can even be shared in their form, but not in their number, since the result of estimates of the mean evolutionary divergence within the Oshi group were so low.

Since no relationship between genetic distance and geographic distance was made in this study, the lack of gene flow (observed by non-haplotypic sharing) should be supported by the presence of geographic barriers. The estimators $\theta$, although being extremely sensitive to any form of molecular variation ( $F u$, 1997), supported the uniformity between the results found by all the methodologies employed, and can be interpreted as a phylogenetic confirmation that there is no consensus in the conservation of the gene of human immunodeficiency virus integrase 1 in samples from the same geographical region, being therefore safe to state that the large number of polymorphisms existing , should be reflected, including, in its protein product (integrase enzyme). This consideration provides certainty that an efficient response of drugs that destabilize the integrase-importin link such as ivermectin should not be expected for all HIV1 viruses from humans, whether they come from the same geographic region (as this study shows), or even more from samples from geographically distinct regions and thus, by extrapolating the levels of polymorphism and molecular diversity found in the samples of this study, for other RNA viruses, such as Sars-Cov-2, the integrase-importin relationship may be even more diverse, and may bring less and less functionality to drugs that interact with it in the role of destabilizing the integrase-importin complex, which in turn inhibit or reduce the infectious potential of any RNA virus.

\section{Declarations}

I am the sole author of the manuscript "HIV-1 versus SARS-CoV-2 infection: understanding the population genetic aspects of drug inefficacy (especially ivermectin) in the integrase-importin complex" and declare that there are no competing interests.

\section{References}


Beale K.K., Robinson WE Jr. Combinations of reverse transcriptase, protease, and integrase inhibitors can be synergistic in vitro against drugsensitive and RT inhibitor-resistant molecular clones of HIV-1. Antiviral Res. 2000; 46:223-32.

Boldescu V, Behnam MAM, Vasilakis N, Klein CD. Broad-spectrum agents for flaviviral infections: dengue, Zika and beyond. Nat Rev Drug Discov. 2017; 16:565- 586.

BRASIL. Ministério da Saúde. COVID-19 NO BRASIL. Dados do setor. Brasília, 2020. Disponível em: https://susanalitico.saude.gov.br/extensions/covid-19_html/covid-19_html.html. Acesso em: 10/07/2020.

Caly, L; Julian D. Druce, Mike G. Catton, David A. Jans, Kylie M. Wagstaff,The FDA- approved drug ivermectin inhibits the replication of SARS-CoV-2 in vitro,Antiviral Research,Volume 178,2020,104787,ISSN 0166-3542,https://doi.org/10.1016/j.antiviral.2020.104787. (http://www.sciencedirect.com/science/article/pii/S0166354220302011.

Cao B, Wang Y, Wen D,et al. A Trial of Lopinavir-Ritonavir in Adults Hospitalized with Severe Covid-19. N Engl J Med. 2020 Mar 18. doi: 10.1056/NEJMoa2001282.

Crooks G.E., Hon G, Chandonia JM, Brenner SE WebLogo: A sequence logo generator,Genome Research, 14:1188-1190, (2004).

Crump A. Ivermectin: enigmatic multifaceted 'wonder' drug continues to surprise and exceed expectations. J Antibiot (Tokyo). 2017 May;70(5):495-505.

Eduardo $S$. Uso de inibidores da integrase como agentes de primeira linha no tratamento da infecção pelo HIV. BJID. Educação Médica Continuada. Vol 2 • № 4 • Agosto 2016. Disponivel em:

https://www.elsevier.es/pt-revista-the-brazilian-journal- infectious-diseases-269-articulo-uso-inibidores-daintegrase-como- X2177511716574464. Acessafo em: 06 de julho de 2020.

Ferner R.E., Aronson JK. Chloroquine and hydroxychloroquine in covid-19. BMJ. 2020 Apr 8;369:m1432. doi: 10.1136/bmj.m1432.

Frieman, M., Yount, B., Heise, M., Kopecky-Bromberg, S.A., Palese, P., Baric, R.S., Severe acute respiratory syndrome coronavirus ORF6 antagonizes STAT1 function by sequestering nuclear import factors on the rough endoplasmic reticulum/Golgimembrane, J Virol, 81 (18) (2007), pp. 9812-9824.

Grein J, Ohmagari N, Shin D, Compassionate Use of Remdesivir for Patients with Severe Covid19. N Engl J Med. 2020 Apr 10. doi:10.1056/NEJMoa2007016.

Kumar S, Stecher G, Li M, Knyaz C, and Tamura K. MEGA X: Molecular Evolutionary Genetics Analysis across computing platforms. (2018). Molecular Biology and Evolution 35:1547-1549.

Nei M. and Kumar S. (2000). Molecular Evolution and Phylogenetics. Oxford University Press, New York. 
OMS. Organização Mundial de Saúde. Genebra: OMS, 2020.

Patel, A.N; Desai, S.S.; Grainger, D.W.; Mehra, M.R. 2020. Usefulness of Ivermectin in COVID-19 Illness. Disponível em: https://www.google.com/url?sa=t\&source=web\&rct=j\&url=http://www.proyectodime.i nfo/documents/219/Utilidad_de_la_ivermectina.pdf\&ved=2ahUKEwjOjJ-

SudTpAhUaCrkGHahuAxkQFjAHegQICBAB\&usg=AOvVaw2dLQryr8gQxSZFATZv YSo3. Acessado em 15/06/2020.

Puras Lutzke RA, Eppens NA, Weber PA, et al. Identification of a hexapeptide inhibitor of the human immunodeficiency vírus integrase protein by using a combinatorial chemical library. Proc Natl Acad Sci USA. 1995; 92:11456-60.

Reinke R1, Steffen NR, Robinson WE Jr. Natural selection results in conservation of HIV-1 integrase activity despite sequence variability. AIDS. 2001;15:823-30.

Robinson WE Jr. L-chicoric acid, an inhibitor of human immunodeficiency vírus type 1 (HIV-1) integrase, improves on the in vitro anti-HIV-1 effect of Zidovudine plus a protease inhibitor (AG1350). Antiviral Res. 1998; 39:101-11.

Schneider TD, Stephens RM. 1990. Sequence Logos: A New Way to Display Consensus Sequences. Nucleic Acids Res. 18:6097-6100.

Smart T. The first integrase inhibitor. GMHC Treat Issues. 1996; 10:8-9.

Tamura K. (1992). Estimation of the number of nucleotide substitutions when there are strong transitiontransversion and G + C-content biases. Molecular Biology and Evolution 9:678-687.

\section{Figures}

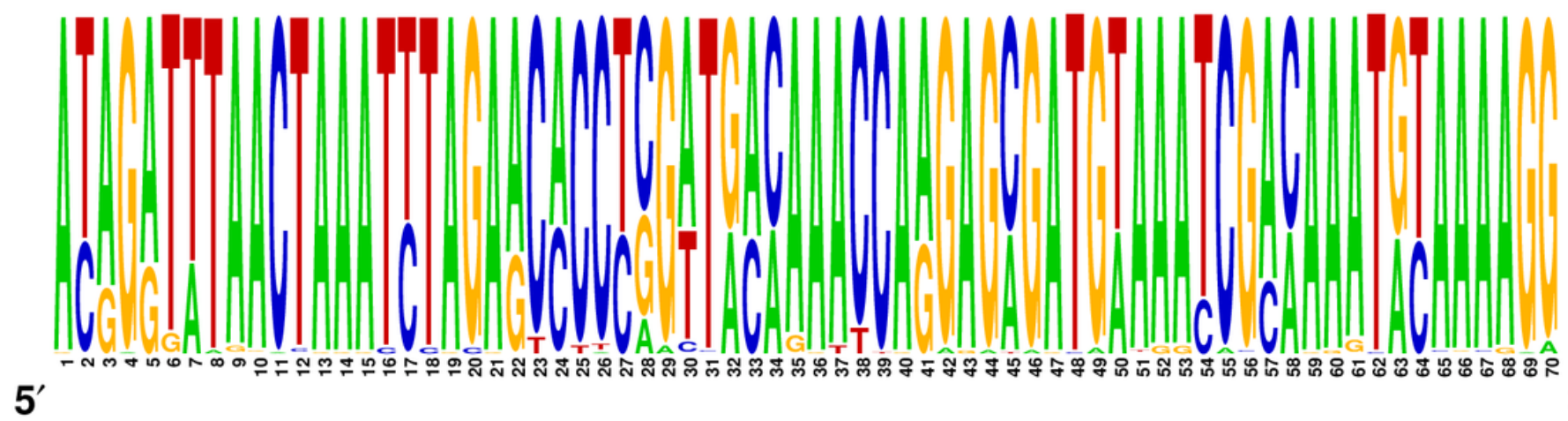

weblogo.berkeley.edu

Figure 1

Graphic representation of 70 parsimonious-informative sites of the integrase gene of human immunodeficiency virus 1 . 


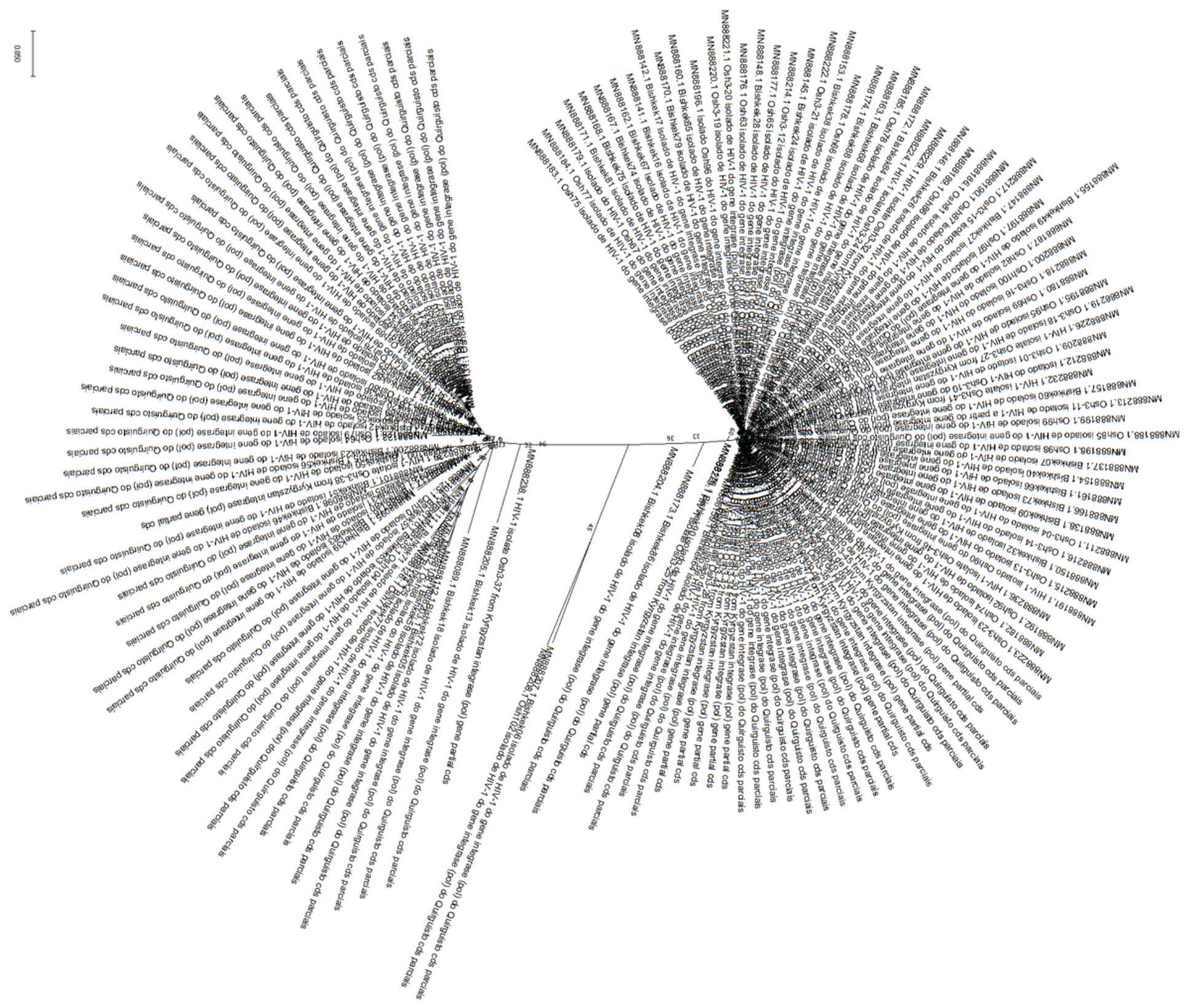

Figure 2

Evolutionary analysis by the maximum likelihood method. The evolutionary history was inferred using the Maximum Likelihood method and the Tamura 3-parameter model [1]. The tree with the highest probability of logging (-1366.35) is shown. The percentage of trees in which the associated taxa group is shown next to the branches. The initial trees for heuristic search were obtained automatically by applying the JoinJoin and BioNJ algorithms to an array of distances in estimated pairs using the Tamura 3 parameter model, and then selecting the topology with a higher log probability value. This analysis involved 153 nucleotide sequences. There was a total of 70 positions in the final dataset. Evolutionary analyses were performed on MEGA X. 